\title{
Difficulties of Summarizing and Paraphrasing in English as a Foreign Language (EFL): Saudi Graduate Students' Perspectives
}

\author{
Arwa O. Alaofi \\ Department of English Language and Translation \\ Qassim University, Buraydah, Saudi Arabia
}

\begin{abstract}
Received: August 27, 2020 Accepted: September 30, 2020 Published: October 5, 2020
doi:10.5296/ijele.v8i2.17788 URL: https://doi.org/10.5296/ijele.v8i2.17788
\end{abstract}

\begin{abstract}
This study examined the major challenges that graduate students ordinarily encounter when it comes to summarizing and paraphrasing source texts. Drawing upon a qualitative methodology, nine Saudi students who were pursuing their graduate degrees in various disciplines have been interviewed. The study findings have shown that various sources of impediments could aggravate students' difficulties in the skills under investigation. These were: Students' inadequate level of English proficiency as the first area to cause difficulties in summarizing and paraphrasing source texts, problems pertaining to students' writing styles as the second, and third, poor reading comprehension skills. However, multiple listening to the interviews and careful analysis of the transcripts produced for these revealed that the challenges faced by students in summarizing and paraphrasing could be enhanced by a further important factor that feed into students struggles with these skills, that is, fear of committing plagiarism. Constantly being in doubt whether the paraphrases that they produce are legitimized or not makes the process of paraphrasing even harder for them. Possible strategies to cope with these difficulties are also provided in this study. The findings presented in this study add to our understanding of the challenges that writing in an academic genre poses for graduate students. Furthermore, these findings send important practical implications for decision-makers in higher studies institutions.
\end{abstract}

Keywords: Summarizing and paraphrasing, academic writing, graduate students, academic writing, English as a foreign language, higher education, learner difficulty 


\section{Introduction}

Academic writing refers to forms of writing that are completed by students in their pursuit of fulfilling a university requirement (Shannon, 2011). It aims to manifest students' content and analytical skills that are perceived as essential requirements for entry into their profession (Shannon, 2011). For Aydin and Baysan (2018), however, academic writing "is an activity to be realized by individuals who have gained a high level of language awareness to organize their knowledge and experience through mental processes" (p. 214). Teaching such a skill is a very significant demand for English-as-a-second-language (ESL) students and English-as-a-foreign-language (EFL) students to attend to the requirements of their degree such as writing essays and research papers (Cai, 2013; Soehadi, 2008). However, academic writing may also be a crucial skill for students who majored in other disciplines that are taught in English, especially at the postgraduate level, where students are expected to produce a variety of works and term papers eloquently and lucidly

Nevertheless, besides being a pivotal skill for these students, academic writing may also be a major dilemma for a considerable population of undergraduate and postgraduate students around the world, even those who are in English majors. This issue has attracted the attention of several researchers in the field of applied linguistics, especially English for specific purposes (Alhojailan, 2015; Cai, 2013; Ratnawati et al., 2018), to name but a few. These studies highlighted a considerable number of difficulties in academic writing that have been experienced by students of various disciplines in different universities around the globe. These problems could be at the language level and the organizational level of academic papers, as well as related to the time allocated to the writing tasks in which students may be subjected to time pressure that could negatively affect the quality of their writing (Alhojailan, 2015; Cai, 2013; Ratnawati et al., 2018). These findings suggested that in both undergraduate and postgraduate levels, students might not be afforded with the required institutional support that facilitates their academic writing skills and makes their college writing experience less arduous. Another possible explanation could be that students themselves, however, might not be investing a considerable amount of time and effort to learn the various conventions of academic writing and to develop their language competency.

Though a considerable amount of literature has examined the general difficulties in academic writing as perceived by undergraduate and postgraduate students, there has been less empirical research on the essential skills in academic writing, such as paraphrasing and summarizing skills. Besides, a few studies shed light on how students perceive such skills in academic settings.

Summarizing, as Murphy (2010) put it, involves presenting another author's primary ideas concisely while adhering to his original style and voice. Paraphrasing also involves presenting the ideas of another author, yet, this presentation is in one's own wording and style (Murphy, 2010). The significance of paraphrasing might lay in its indispensable role "in developing and supporting a scholarly argument" (Murphy, 2010, p. 13).

Students in the academic domains are expected to produce a variety of term papers, which generally involve relying on further external sources such as books, theses, journal articles, 
and the like. Notwithstanding, students are also expected to adhere to the ethics of the academy, among which, giving credit to the original authors of the works they based their papers on, i.e., citation and referencing. This, however, cannot be achieved but by a complete mastery of summarizing and paraphrasing strategies.

According to Nambiar (2007), Summarizing is a cognitively demanding job as it requires the students to reconceptualize the text that they have read through the process of going back and forth in the text and viewing it from a more general macro level, rather than a local micro one. Also, it requires the students to have a good grasp of the main ideas of the text and to distinguish the important superordinate elements from the less important, subordinate ones (Nambiar, 2007). In this decision-making process, students might be best facilitated with the crucial skill of reading comprehension that can enable them to allocate relevant details and exclude irrelevant ones (Flores \& Lopez, 2019). It should be noted that, however, the key distinguishing feature that differentiates a paraphrase from a summary is that in paraphrase, the focus is "on restating the ideas, not condensing them" (Horkoff, 2015, p.81).

Despite their indispensability for successful academic writing, ESL students and EFL students encounter various challenges when trying to use summaries and paraphrases in their universities' requirements (Adi Badiozaman, 2014; Flores \& Lopez, 2019). These include difficulties at the language level (for example, finding an appropriate synonymy), difficulties at the level of reading comprehension (e.g., identifying main ideas in the text), and finally, difficulties related to documentation skills (citation and referencing, for example).

\subsection{Problem of The Study}

Graduate students' incorporation of source texts into their writing has extensively been researched in plagiarism-related studies (e.g., White, 1993). These studies took a process-oriented approach as they directly ask why students' writings would involve such an unethical use of material sources. These studies, in other words, examined students' academic products rather than their academic experiences that may lead to such kinds of insufficiencies in their academic behaviors.

Addressing graduate students' perspectives about their experiences in academic writing, especially in textual borrowing, constitutes a preliminary step in solving ethical concerns in the academy. Since those are the primary agents behind these issues, exploring their perspectives concerning the aspects that influence their abilities to incorporate source materials correctly, effectively and ethically in their papers seems important. Such investigations could provide answers that have long been sought after in the field.

Crucial initiatives in this regard were taken by Flores and Lopez (2019), and Adi Badiozaman (2014), who interviewed several learners studying in EFL contexts, where achieving an appropriate level of academic literacy was mandatory. As expected, students in their studies maintained that practicing paraphrasing and summarizing when working with source texts was not immune from challenges. Notwithstanding, the students who reported these challenges were pursuing either their bachelor or diploma degrees, hence, the picture around 
the kinds of difficulties that graduate students suffer regarding these two skills remains unclear.

In Saudi Arabia, significant reforms have been made in the educational sector, despite that, the English skills, specifically writing, of Saudi students are still below the global standards (Alshammari, 2020). Several attempts have been made to understand the factors that could influence Saudi students' academic writing products (e.g., Al Fadda, 2012, Qayoom \& Saleem, 2020). However, these studies have not provided clear insights about the struggles that Saudi graduate students encounter, precisely, in summarizing and paraphrasing. In other words, studies in this area have mostly addressed students' perceptions of academic writing, along with the common struggles that they suffered while writing in this genre. Accordingly, need still exists to explore the challenges that Saudi graduate students regularly face in these two skills that constitute important aspects of their academic writing proficiency. Moreover, addressing their difficulties in these crucial skills might provide rational justifications for the general problems that they encounter while writing academically. With that being said, the present study aims to explore the difficulties that Saudi graduate students encounter in summarizing and paraphrasing, hoping that this will add to the growing body of literature on graduate students' experience in academic writing.

\subsection{Research Questions}

The present study attempts to fill a pertinent gap in the literature of academic writing by answering the following questions:

1. What are the main challenges that Saudi graduate students encounter while summarizing and paraphrasing source texts in English?

2. What are the possible solutions/strategies for Saudi graduate students to overcome the challenges of summarizing and paraphrasing source texts in English?

\subsection{Significance of Research}

By exploring graduate students' perspectives concerning the arduousness that they experience in the two most critical skills in academic writing, that is, summarizing and paraphrasing, the present study shines new light on the debate of graduate students and academic writing.

The study also gains certain importance in the Saudi context since no previous research, to the best of the researcher's knowledge, has dealt primarily with the challenges that these two skills pose for Saudi graduate students.

Besides exploring the kinds of difficulties that graduate students encounter while summarizing and paraphrasing other authors' texts, this study forwards important pedagogical implications by exploring possible solutions and suggested strategies that could be exploited in dealing with the challenges that these two skills pose for students.

\section{Literature Review}

During the past two decades, researchers in applied linguistics have shown an accelerated interest in issues of students' academic writing. Those researchers, nevertheless, chose to 
investigate this area from a variety of different angles. That is, some of them were interested in analyzing students' needs so that they can come to produce a better academic writing quality (Lung et al., 2014). Others, however, were concerned with the psychological factors that might affect the quality of students' writing, such as anxiety (Aloairdhi, 2019). Nonetheless, in a broader scope of interest, many researchers worldwide (Al Fadda, 2012; Cai, 2013; Ratnawati et al., 2018) were preoccupied with students' perceptions and perspectives of academic writing along with the salient difficulties that they encounter while writing in this genre. This pre-occupation has transpired because, despite their non-native linguistic competencies, students in ESL/EFL contexts are expected to exert both disciplinary knowledge and knowledge of the conventions of academic writing (Alhojailan, 2015). With such knowledge, students will be able to produce efficient academic papers while writing in their disciplines (Alhojailan, 2015).

Since the present study aims to investigate graduate students' struggles with paraphrasing and summarizing skills that constitute indisputable aspects of graduate students' academic writing competency, the literature review starts with some studies that address students' difficulties in academic writing in general. First, it reviews studies that addressed Asian undergraduate and graduate students' difficulties in academic writing in EFL contexts. Then, it narrows down the scope of the studies to cover those related to Saudi graduate students in EFL contexts. Next, it discusses what the literature, which is scarce, has revealed about graduate students' perceived struggles with paraphrasing and summarizing in academic writing.

\subsection{Students' Difficulties in Academic Writing in EFL/ESL Contexts}

\subsubsection{Asian Students' Difficulties in Academic Writing}

Using questionnaires and focused group interviews, Cai (2013) investigated the challenges that academic writing poses for Chinese EFL graduate students. Students in this study reported that they encountered some severe problems while writing their university courses' requirements. These included problems related to their research abilities (e.g., reviewing previous literature, criticizing it, and allocating research gaps in that literature). Also, they reported problems in writing methodology and discussion sections in their research papers. However, as far as language-related problems were concerned, students in this study exhibited confidence regarding their usage of grammar. However, they reported some struggles when it came to achieving appropriacy in academic writing in terms of proper usage of lexical phrases that link distinct sentences and paragraphs and in understanding the conventions of the academic genre, which can be classified as stylistic problems.

Using similar instruments, Ratnawati et al. (2018) investigated Indonesian EFL undergraduate students' perceptions concerning the difficulties they confronted while writing academically. However, unlike the students in Cai's (2013) study, those in Ratnawati et al.'s (2018) study suffered significantly from language-related problems (e.g., problems in using grammar properly, problems in relation to their vocabulary repertoire). One possible explanation for this discrepancy in findings could be the different educational levels of the samples in the two studies, that is, while Cai's sample was graduate students, Ratnawati et al.'s sample was undergraduate students. Therefore, it could be inferred that graduate students 
might have experienced fewer language difficulties compared to undergraduate students.

Nevertheless, despite their different levels, just like those in Cai's (2013) study, students in Ratnawati et al.'s (2018) study expressed some concerns about stylistic issues (e.g., developing coherent and cohesive paragraphs, and writing them in a proper order). Also, students in Ratnawati et al.'s (2018) study revealed that they tended to confront challenges in expressing and conveying their ideas into written academic mode, i.e., communication difficulties, which can be, according to Ratnawati et al.'s (2018), the result of both language and style problems. Finally, like those in Cai's (2013) study, students in Ratnawati et al.'s (2018) study acknowledged some difficulties when it came to writing different sections of the research paper.

\subsubsection{Saudi Graduate Students' Difficulties in Academic Writing}

Using interviews, Alhojailan (2015) sought to investigate challenges in academic writing as perceived by international Saudi graduate students in different American universities. Students in his study indicated that the challenges that they encountered in academic writing stemmed from various sources of struggles. For example, they reported some difficulties in relation to grammar (language-related problem), difficulties in vocabulary (language-related problem), and difficulties at the organizational level of academic writing, such as, developing and writing various sections of an academic paper.

Through questionnaires administrated to 50 Saudi students at King Saud University, Al Fadda (2012) pointed out that graduate students struggled mainly with the formal aspects of language such as grammar and lexis. These difficulties were similar to those experienced by students in Alhojailan's (2015) study. Also, students in Al Fadda's (2012) study revealed that they faced difficulties in achieving appropriate styles of writing, such as linking sentences in paragraphs in a suitable manner.

Almarwani (2020) utilized semi-structured focus group interviews to explore academic writing challenges that were faced by Saudi postgraduate students who were enrolled in a teaching English to speakers of other languages (TESOL) program. Students in his study expressed a sense of dissatisfaction when it came to the quality of their academic writing. Such dissatisfaction stemmed mainly from various problematic areas, such as, poor English proficiency, insufficient academic writing skills, and lack of source-managing skills.

Collectively, this handful of studies have demonstrated that second language (L2) writers, being undergraduate students or graduate ones, ordinarily experience a hard time when writing their various university's papers, including their research papers. The primary sources of these struggles, as the studies reviewed above suggested, include aspects related to students' proficiency in the second language, for example, their grammatical proficiency and vocabulary repertoire. Other sources of these difficulties have to do with students' writing proficiency; these include stylistic aspects of writing, for example, developing well-organized and coherent paragraphs. The assumption that these are related to their writing proficiency, rather than to their language proficiency was drawn based on the notion that being a proficient writer does not necessarily entail being a proficient speaker (Hubert, 2013). A final 
source of obstacles for students in academic writing, however, has to do with their inadequate familiarity with the genre of academic writing. As the research presented in this section indicates, students usually find it challenging to develop various parts of a research paper, for instance, the Introduction and the Methodology sections.

\subsection{Difficulties of Summarizing and Paraphrasing in Academic Writing}

One of the most important dimensions of academic writing instruction involves developing students' abilities to incorporate source texts into their papers (Hirvela \& Du, 2013). Such importance stems from the fact that paraphrasing, rather than direct quotation, is perceived as an important marker of a student's understating of given scholarly materials, especially more complicated ones (Hirvela \& Du, 2013). Additionally, paraphrasing is commonly seen as an efficient plagiarism-avoiding strategy (Stander, 2020). These skills, summarizing and paraphrasing, are also important for scholarly publications in different disciplines (Howard et al., 2010).

At the same time, nevertheless, many L2 students were reported to find paraphrasing and summarizing as one of the most daunting skills in academic writing (Flores \& Lopez, 2019; Lin \& Maarof, 2013). For instance, Keck (2006) compared summaries written by L1 writers and L2 writers to explore how students within the two groups made paraphrases from the original texts that were summarized, and whether there was a significant difference in the types of paraphrases in the texts composed by students in the two groups exists.

After analyzing the papers produced by these students, Keck (2006) found that the summaries that were produced by L2 writers contained more exact copies from the original excerpts. Furthermore, L2 writers made substantially more near copies paraphrases in their summaries, on the contrary, the majority of L1 writers' summaries did not contain this type of paraphrase. Additionally, L1 writers in Keck's (2006) study seemed to make more substantial changes to the original experts in paraphrased sentences within their summaries than did L2 writers. Arguably, these findings may work as an illustrative point of how the struggle with summarizing and paraphrasing in academic writing could be even worse for L2 writers.

Instead of analyzing students' papers and comparing them with the original papers, Flores and Lopez (2019) tried to address L2 students' problems in summarizing and paraphrasing by directly asking them to self-report their struggles in the skills under question. Students in Flores and Lopez's (2019) study numerated various causes of impediments in summarizing and paraphrasing, mainly, students' inadequate level of English proficiency, poor reading comprehension skills, insufficient vocabulary repertoire, and deficient documentation skills. It should be noted that time pressure was also identified as an obstacle that could affect students' performance while summarizing and paraphrasing, as reported in Flores and Lopez's (2019) study.

Adi Badiozaman (2014) interviewed two Malaysian L2 students who were taking a diploma program in Business to investigate the difficulties that they encountered when paraphrasing source materials. Students in Adi Badiozaman (2014) study reported copious challenges that they faced when it came to paraphrasing. These challenges were mainly related to their low 
level of English proficiency that affected their knowledge of appropriate grammatical structures and their lexical repertoire. Furthermore, these students acknowledged confronting difficulties in comprehending source materials and retaining the original author's intended meanings in their paraphrases, especially when the source text addressed a new topic with which they were unfamiliar.

In combination with these areas of difficulties, students in Adi Badiozaman (2014) study expressed their fear of committing plagiarism as a result of misapplying the rules of paraphrasing. Despite this fear, however, Adi Badiozaman (2014) noted that during the interviews, one of these students seemed to have a misunderstanding of what a correct paraphrase actually was.

These two studies, Flores and Lopez (2019) and Adi Badiozaman (2014), are of great significance as they mark initial attempts to enhance our understanding of the sources of struggles for students when it comes to paraphrasing and summarizing. However, the students who reported such difficulties were pursuing either their bachelor degrees or diploma degrees. Therefore, graduate students' difficulties in these skills are yet to be understood.

\section{Method}

\subsection{The Research Design}

This study aims to examine Saudi graduate students' perspectives on paraphrasing and summarizing and to explore the various difficulties that they confront while working with source materials. To that end, the present study draws upon a qualitative research design. Leedy and Ormrod (2015) pointed out that "qualitative designs can be quite helpful for addressing exploratory or interpretive research questions" (p. 101). This exploratory nature of the qualitative approach seems to be the most effective tool that can be utilized in serving the objectives of this study.

\subsection{Participants}

The study sample consisted of nine Saudi female students, ranging from 23 to 32 years old, who were enrolled in different Masters programs at various universities in Saudi Arabia. In particular, six of them were pursuing degrees in Applied Linguistics, one in Business Administration, one in Chemistry, and one in Clinical Psychology.

Out of the nine participants, only two participants were in their first semester in Masters programs, the rest of them were either about to finish their first year or are already in their second year in the graduate program.

A purposive sampling was employed to sample students who took part in this study. With purposive sampling, researchers rely on their knowledge of the study's population to elicit data that can be used as a source of evidence in their studies (Mackey \& Gass, 2005). That being so, using this sampling procedure allowed the researcher to only recruit participants who were enrolled in programs where an extensive amount of assignments is to be written before thesis writing. 


\subsection{Instruments}

A semi-structured one-to-one interview was utilized as the main data elicitation instrument in this study. According to Leedy \& Ormrod (2015), when using a semi-structured interview, "the researcher may follow the standard questions with one or more individually tailored questions to get clarification or probe a person's reasoning" (p. 160). Since the main purpose of this study was to reach for students' experiences with summarizing and paraphrasing, semi-structured interviews were employed to allow the researcher to gain a more in-depth understanding of students' perspectives by asking more illuminating questions when needed (rather than following a strict question-answer protocol).

The present study was carried out during the Covid-19 pandemic, therefore, all of the interviews were conducted via phone calls. The duration of the interviews ranged between 15 to 26 minutes (depending on the amount of the illuminating questions that were asked by the researcher). Since both the researcher and the interviewees are all native speakers of Arabic, the majority of interviews were conducted in Arabic then translated into English (the only interview conducted in English was with an Arabic speaker who was majored in English and who has already achieved advanced fluency in English). Conducting interviews in the mother tongue of the participants could give them a better chance for expressing ideas and sharing experiences freely without the language barrier being a factor in this respect. The interview question form is presented in the Appendix.

\subsection{Procedures}

Interviews were recorded using a voice recorder application, after that, they were transcribed manually. To ensure validity, the researcher listened more than one time to each recording. Transcripts were examined thoroughly to obtain initial categories. Multiple analytical readings of the transcripts helped to put together identical categories. From these categories, two major themes under which students' concerns regarding summarizing and paraphrasing have been generated. Under the first theme, problems related to students' general proficiency in academic writing have been coded. For example, when a participant reported difficulty in finding equivalent terms when paraphrasing, this issue was categorized as a language problem, specifically, vocabulary related one. When another participant expressed difficulty in understanding source materials, this was classified as a reading comprehension problem. And finally, when the challenges that the participants have faced in these two skills were the result of their writing style (and how they can paraphrase source materials and summarize them without violating their personal style's conventions), these were classified as stylistic problems. That being so, students' reported challenges in summarizing and paraphrasing were classified under one of the following categories in the first theme: Language-related problems, style-related problems, and reading comprehension problems.

The second theme that has emerged from data in this study was students' noticeable fear of unintentionally committing plagiarism. During the interviews, the researcher was able to infer this fear from their answers. Although participants were not asked either directly or indirectly about such issue, it was apparent that plagiarism is a major source of an impediment for them 
when dealing with source materials. Such concern was explicitly expressed in answers like "I am always worried that I [unintentionally] commit plagiarism".

\section{Results}

The present study aims to investigate the challenges that Saudi graduate students encounter when summarizing and paraphrasing materials from outside sources along with the possible strategies and solutions that could be exploited in overcoming these challenges. A careful analysis of the interviews' transcripts allows for the emergence of two main sources of difficulties that can combine together in feeding into students' challenges in these skills. These sources are: First, issues related to students' language proficiency, writing style, and reading comprehension, and second, fear of committing plagiarism. With that being said, this section reports the findings regarding the sources of students' struggles in these two skills. Furthermore, it presents suggested solutions in order to cope with these difficulties as pointed out by students during the interviews.

\subsection{Primary Sources of Students' Struggles in Summarizing and Paraphrasing}

Table 1. Areas of difficulties in summarizing and paraphrasing

\begin{tabular}{lll}
\hline Difficulty type & $\%$ & Sample quote \\
\hline Language-related problem & $90 \%$ & $\begin{array}{l}\text { E.g., "I do not know how to } \\
\text { change the word", "I } \\
\text { struggle with finding } \\
\text { equivalent words and I also } \\
\text { struggle with the grammar." }\end{array}$ \\
\hline Style-related problem & E.g., "I am trying to come up \\
& with a piece of writing that \\
& fits my own style of writing. \\
& I do not prefer mimicking \\
& & others' styles. I cannot, I \\
& cannot write in their own \\
Reading & style." \\
problem & E.g., "It has to do with the \\
& genre [of the text to be \\
& summarized] because I am \\
& familiar with certain genres \\
& but not others." \\
\hline
\end{tabular}

Table 2. Language-related problems

\begin{tabular}{ll}
\hline Area of difficulty & $\%$ \\
\hline Vocabulary & $87 \%$ \\
\hline Expressing ideas in clear manner & $37 \%$ \\
\hline Grammar & $25 \%$ \\
\hline
\end{tabular}


As was elucidated above, the participants' answers during the interviews indicated that their struggles in the two skills in question could be interpreted in terms of two main areas of difficulties. Under the first area that has to do with students' general competencies in academic writing, students reported that the challenges that they face when summarizing and paraphrasing could particularly be attributed to three major sources of difficulties. These sources are: First, Problems related to students' language proficiency as the major source of difficulties in summarizing and paraphrasing, second, problems related to their style of writing, and third, problems relevant to their abilities to comprehend a given piece of text.

When it comes to issues pertaining to their language proficiency, 90\% of the interviewees maintained that they encountered difficulties in academic writing in general and in summarizing and paraphrasing in specific due to their inadequate level of EFL proficiency. In specific, $87 \%$ of the participants indicated that they had problems related to their vocabulary repertoire, and $37 \%$ of them expressed difficulties in restructuring the original author's ideas clearly and appropriately in their own words without violating their meanings. For example, when asked about the most daunting difficulties they encountered in summarizing and paraphrasing, one interviewee answered: "Finding alternative words, and restructuring the sentence in a good way." Another participant commented, "I always struggle when trying to find appropriate synonyms." It should be noted that only $25 \%$ of the total number of interviewees who suffered language-related problems reported difficulties with the English grammar.

Of the total number of participants in this study, 33\% attributed their struggles in the skills under investigation to their style of writing. They found it difficult, and even unacceptable, to deviate from their writing style, which might disturb the flow of their writing, as they claim. These stylistic issues arise, for example, when they faced a text composed by a writer who have a largely similar style to their own style. In this respect, one interviewee said, "I cannot paraphrase because what I want to write is there." Others, however, claimed that they cannot mimic others' writing styles, hence, paraphrasing a piece of writing costs them a lot of time and effort.

Besides language and stylistic issues, comprehending a given text comes to be a further source of struggles for the participants in this study. $22 \%$ of the interviewees who were questioned indicated that being unable to understand the material to be summarized or paraphrased constituted one of their main salient difficulties when it comes to academic writing, whether this inability was due to their unfamiliarity with the genre of the text or because the text itself was written in a completely different field from theirs. Table 1 and Table 2 illustrate these findings.

Aside from these three issues, recurrent listening to their answers during the interviews and an analytical reading of the transcripts produced for these showed that there is another important issue that could play a serious role in feeding into students' challenges with these skills, that is, fear of committing plagiarism. Approximately, over half of the participants in this study maintained that they were not always confident that their writing was plagiarism free. Therefore, they constantly encountered difficulties when it came to academic writing in 
general and paraphrasing in particular. Expressing her concern in this regard, one interviewee said, "one issue that I always find ambiguous and I am always worried that I unintentionally commit is plagiarism."

Surprisingly, and despite their apparent fear of committing such academic misconduct, a few participants seemed to be not fully aware of what actually constituted a legitimized paraphrase. In response to questions about their approaches in paraphrasing, these students reported that they merely made surface level changes on the original text, for example, substituting words and using alternative synonyms.

Besides the areas of struggles stated above, however, time pressure and firm deadlines have been identified as factors of an influential impact on students' performance while summarizing and paraphrasing. $77 \%$ of the participants indicated that being put under pressure affected both the quantity and the quality of their writing, thus, ending up with non-inclusive summaries.

Nevertheless, in a somewhat surprising finding, $22 \%$ of the participants claimed that they worked better when put under pressure. Worth quoting here is one interviewee comment about the effect of time pressure on her writing performance:

"Time does affect my ability to paraphrase and summarize, in some cases positively, sometimes, when I am put under pressure, I would master every energy I have and produce something of a good quality in such a short time."

\subsection{Strategies for Addressing Summarizing and Paraphrasing Difficulties}

In combination with its goal of investigating the major challenges that Saudi graduate students encounter in summarizing and paraphrasing, the study also aimed at exploring effective solutions and strategies that students normally employ to cope with these challenges. Interestingly, students interviewed in this study seemed to have a solid grasp of the sources of their struggles. Accordingly, they reported numerous solutions and strategies that they constantly utilized when they found themselves being hindered by any of these difficulties. These strategies are: Practicing summarizing and paraphrasing more, searching for appropriate equivalents when struggling with vocabulary, doing more readings in the genres or fields that they do not comprehend, re-summarizing their writings until they come up with concise papers, making direct quotations in order to keep their writing style consistent, revising produced materials, having someone else proofread their papers, and finally, seeking the help of their advisors.

In addition to these individual strategies, participants also placed a higher emphasis on the role of universities in developing the students' paraphrasing and summarizing skills in specific and their academic writing in general. They suggested that, for instance, the university should offer courses in advanced academic writing, and arrange periodically workshops that could tackle the basics of academic writing. 


\section{Discussion}

Students who were interviewed in the present study reported various reasons behind the struggles that they ordinarily encounter in summarizing and paraphrasing. Far more common than any other source of difficulty in students' answers were their different problems at the language level. Language problems were also a major source of challenges in summarizing and paraphrasing for students in Flores and Lopez's (2019) study and students in Adi Badiozaman's (2014) study. However, of the various types of problems in their language proficiency, including problems in grammar and problems in restructuring new sentences, vocabularies came to be the most salient language area where students face real struggles. When it comes to their linguistic repertoire, students who were interviewed in the present study expressed the feeling that the vocabulary that they always use in their papers are not truly powerful academic vocabulary. They think that these, as they put it, are common and ordinary ones. Hence, they feel the need to gain more academic vocabulary to incorporate in their texts. Concerns about academic words have also been expressed by one of the Saudi graduate students in Alhojailan's (2015) study.

As pointed out above, grammar constituted a problem for only $25 \%$ of the participants in this study. For the rest of them, however, language problems were generally related to their linguistic, and mostly academic repertoire. One possible explanation for this finding is that, at this level, students have mostly mastered the basics of English. Therefore, increasing their vocabulary repertoire is all they need to have various options when confronting a piece of text that they need to paraphrase or summarize. Another possible explanation for this finding could be that these students, despite their advanced levels, might not have achieved a complete familiarity with the genres of academic writing yet.

Besides problems pertaining to their language proficiency, stylistic problems came to play a considerable role in students' struggles with summarizing and paraphrasing. Stylistic issues, as their answers suggest, manifest themselves differently among different students, hence, affecting them differently in various aspects of writing. One of the participants, for instance, said, "I have been told that my writing is affected by my mother tongue, and I am struggling with this issue." Due to this reason, the participant, who also acknowledged deficiencies in her English proficiency, always finds it difficult to paraphrase other authors' ideas and make them fit into her writing style.

Other participants, who were more advanced in level and who reported fewer language problems, expressed facing difficulties in incorporating source texts into their papers while maintaining their style of writing. They also found it difficult to adhere to the rules and structures of some of the tasks usually assigned to them because these, as they claim, hinder their creative thinking. Expressing her concern in this regard, one interviewee noted, "one difficulty that I face is with the structure of the paper or the assignment, if I have a certain limit, and I am asked to paraphrase or summarize, then I really struggle because as I said I tend to write a lot." For this student, institutional rules of academic writing limit her creativity and affect her approach while summarizing and paraphrasing.

In line with the finding of Flores and Lopez's (2019) study and the findings of Adi Badiozaman's (2014) study, the inability to comprehend a given material also came to be a 
source of an impediment when summarizing and paraphrasing for students in this study. One might think that these issues are due to students' low language proficiency, and this might be true to some extent. However, it should be noted that some of those participants who expressed concerns about comprehending a source text maintained a high level of English proficiency. Hence, they attributed the difficulties that they encounter in reading to factors such as a shift in the genre or the field of a text and authors' different writing styles.

A recurrent listening to the interviews revealed that students' dilemmas in these skills, summarizing and paraphrasing, were also promoted by a further important factor that constantly keeps them in doubt about the paraphrases and summaries that they produce, that is, fear of unintentionally committing plagiarism. Indeed, over half of the participants who took part in this study expressed such concern when asked about what makes the process of borrowing from outside sources harder for them. Similar matters were also expressed by students in Adi Badiozaman's (2014) study.

Students' fear of being accused of this academic dishonesty was manifested in their answers during the interviews, where they indicated that being uncertain whether they made enough changes to the original sentence or not is one of the most daunting aspects of paraphrasing. Also, one of the participants discussed the concept of patchwriting that was coined by Howard (1992) and defined as "copying from a source text and then deleting some words, altering grammatical structures, or plugging in one-for-one synonym substitutes" (p. 233). The participant's concern about this concept may reflect both her high awareness and strict adherence to the rules of academic writing by not wanting to even, unintentionally, commit plagiarism.

Unlike this participant (and also other participants who have exhibited a high degree of awareness of a legitimized paraphrase), however, two other participants in this study, who also expressed their worry about plagiarism, seemed to have both misunderstandings of what can be counted as plagiarism and unfamiliarity with the concept of patchwriting. As their explanations of their paraphrasing practices suggest, these participants seemed to approach what Howard (1992) called 'patchwriting' when utilizing material sources. This finding gives evidence to the notion that not all plagiarizing students are aware that they are violating the rules of the academy, and this might be due to their inadequate understanding of proper strategies of paraphrasing, referencing, and citing (Park, 2003).

Since also some students in Adi Badiozaman's (2014) study and Alhojailan's (2015) study have shown similar misconceptions of accurate paraphrasing, then it might be the case that this is a widely spread and inherent issue among university students.

With respect to the second research question, during the interviews, the researcher noticed that students seemed to be familiar with the sources of their difficulties in summarizing and paraphrasing; hence, they mostly know how to properly address them. For instance, when it comes to their lack of vocabulary, especially when reading in new fields, students mentioned that they search more to solve the issue partly by finding appropriate equivalents in dictionaries or on the Internet, and that they read more and more in that field so that they can acquire its lexis. In order to cope with their stylistic issues, students named solutions like making direct quotations and re-summarizing produced materials so that they can leave out unnecessary details. Students also talked about proofreading produced material and seeking their 
supervisors' guidance as considerable solutions for the challenges encountered in these two skills. These strategies are similar, albeit slightly, to those reported by students in Flores and Lopez's (2019) study.

Despite taking this self-regulated learning approach, which is what is expected from a graduate student, the participants in this study expressed the need to the university support that can come in the shape of specific subjects that teach them the mechanics of academic writing or periodically workshops that train their academic and research skills.

The findings yielded by this research suggest that graduate students' experience with academic writing is not immune from challenges. These challenges could be attributed to a number of reasons, for example, students' inadequate English language proficiency, writing style, obstacles with comprehending reading materials, firm deadlines and time pressure, and fear of unintentionally committing plagiarism. Such challenges could make students' collage experience a daunting one. offering students with the guidance they need could, therefore, lessen the challenges they face in higher studies. Teachers should, for instance, offer students advices as how to best approach source materials, and how to grasp the meanings intended by the original author and render it later in one's own words. It also seems crucial to draw students' attention to a very serious issue in the academy, that is, what is known as patchwriting. Not being fully aware of such academic misconduct may have severe consequences on students' academic journey. Students should also be encouraged to develop a more autonomous learning approach through which they can mindfully handle various issues during their research process.

\section{Conclusion}

The present study aimed at exploring the challenges that Saudi graduate students encounter while summarizing and paraphrasing source materials. To do so, the study drew upon a qualitative methodology in order to reach for students' perspectives in regard to their experiences with these skills. The participants who took part in this study were nine Saudi female students perusing their graduate degrees in various fields. The researcher interviewed these participants, transcribed these interviews, and subsequently analyzed them in order to detect prominent themes.

The study findings revealed that the difficulties that the students commonly encounter in these two skills can be attributed to a number of remarkable sources of impediments. These include students' inadequate language proficiency, poor comprehension of the given source material, and problems related to students' writing styles. As far as the problems relevant to students' language proficiency are concerned, it sounds fair to note that, mostly, these were related to their linguistic repertoire. In other words, most of the students who expressed some concerns about their language proficiency in this study were mainly communicating their excessive need to gain more powerful academic vocabulary.

A second important finding, and also a primary source of students' struggles with summarizing and paraphrasing, in this study was students' apparent fear of unintentionally communicating plagiarism by misapplying the rules of a correct paraphrase. As their answers indicate, continually being unsure about the quality of the paraphrase that they produce 
makes the process of paraphrasing a daunting one for them. Despite this fear, however, $22 \%$ of the participants seemed to be not knowledgeable enough of what constitutes a legitimized paraphrase, in which they reported that they merely substitute words with their equivalents when they were asked about their paraphrasing practices.

In addition to identifying the primary challenges that confront graduate students while summarizing and paraphrasing, the study also sought to investigate the strategies that these students apply in order to address these challenges. The participants reported various solutions for their different problematic areas, among these: Practicing the skills in question more, searching the Internet/dictionaries for appropriate synonyms, reading more in the fields or genres that they face comprehension difficulties in, making direct quotations, re-summarizing their papers, proofreading their work, and seeking their advisors help.

Taken together, the findings of this study contribute significantly to enhancing our understanding of the kinds of struggles that graduate students encounter in academic writing. Specifically, they might be of a practical relevance for material designers and teachers working in higher studies institutions, where a number of student-related decisions are to be made. As an example, teaching practices in academic writing classes should be revisited, considering the kind of materials delivered, and the ways in which such materials are being taught. Teachers should take the time to train students' academic writing skills since these are seen as an important window into their research competencies. Students' support could also come in the form of outside class activities. Universities may, for instance, organize regular workshops or seminars that train students' academic skills, and offer them guidance where needed. Additionally, solutions that were provided by participants in this study may also be of a large benefit to other graduate students struggling with source materials.

Despite its critical contributions to the literature on students and academic writing, the transferability of the findings of this study might be affected by a limitation in regards to its methodology. Clearly, only one data collection method, interview, was employed in this study, thus, conducting further research with more than one method might show different findings. Further researchers could, for example, combine both interviews and diaries in order to gain deeper insights about students' struggles with summarizing and paraphrasing.

The study also has thrown an important question that might be of a high importance for research in graduate students and plagiarism, that is, whether the practice of what is called patchwriting is a widely spread phenomenon among graduate students or not. Given that these findings confirm what has been stated in previous research that not all plagiarizing students are intentionally doing so (e.g., Park, 2003).

\section{References}

Alhojailan, A. (2015). Perceptions of academic writing by some Saudi graduate students studying in American universities [Doctoral dissertation, Oklahoma State University]. OSU SHAREOK Repository https://shareok.org/handle/11244/45334

Almarwani, M. (2020). Academic writing: Challenges and potential solutions. Arab World English Journal (AWEJ) Special Issue on CALL, (6), 114-121. 
https://doi.org/10.24093/awej/call6.8

Alshammari, S. (2020). "Writing to learn or learning to write". A critical review of "English as a foreign language" (EFL) teaching practices in writing in Saudi universities. Research in Education and Learning Innovation Archives, 24, 1-22. https://doi.org/10.7203/realia.24.15867

Al Fadda, H. (2012). Difficulties in academic writing: From the perspective of King Saud University postgraduate students. English Language Teaching, 5(3), 123-130 https://dergipark.org.tr/en/pub/jlls/issue/43364/527967

Aloairdhi, N. M. (2019). Writing anxiety among Saudi female learners at some Saudi universities. English Language Teaching, 12(9), 55-65. https://doi.org/10.5539/elt.v12n9p55.

Aydın, G., \& Baysan, S. (2018). Perceptions of postgraduate students on academic writing skills: A metaphor analysis study. Journal of Language and Linguistic Studies, 14(2), 212-239.

Adi Badiozaman, I. F. (2014). Paraphrasing challenges faced by Malaysian ESL students. Issues in Language Studies, 3(1), 49-69. https://doi.org/10.33736/ils.1662.2014

Cai, L. (2013). Students' perceptions of academic writing: A needs analysis of EAP in China. Language Education in Asia, 4(1), 5-22. https://doi.org/10.5746/leia/13/v4/i1/a2/cai

Flores, E. R., \& Lopez, M. (2019). Self-reported summarizing and paraphrasing difficulties in L2 writing contexts: Some pedagogical interventions. Indonesian Journal of Applied Linguistics, 9(2), 286-296. https://doi.org/10.17509/ijal.v9i2.20219

Hirvela, A., \& Du, Q. (2013). “Why am I paraphrasing?”: Undergraduate ESL writers' engagement with source-based academic writing and reading. Journal of English for Academic Purposes, 12(2), 87-98. https://doi.org/10.1016/j.jeap.2012.11.005

Horkoff, T. (2015). Writing for success: 1st Canadian edition. Bccampus. https://open.bccampus.ca/browse-our-collection/find-open-textbooks/?uuid=8d415c45-41da4c9d-8c9d-ab66bbdd359c\&contributor\&keyword\&subject

Howard, R. M. (1992). A plagiarism pentimento. Journal of Teaching Writing, 11(2), 233-45.

Howard, R. M., Serviss, T., \& Rodrigue, T. K. (2010). Writing from sources, writing from sentences. Writing \& Pedagogy, 2(2), 177-192. https://doi.org/10.1558/wap.v2i2.177

Hubert, M. D. (2013). The development of speaking and writing proficiencies in the Spanish language classroom: A Case study. Foreign Language Annals, 46(1), 88-95. https://doi.org/10.1111/flan.12010

Keck, C. (2006) The use of paraphrase in summary writing: A comparison of L1 and L2 writers. Journal of Second Language Writing 15(4), 261-278. https://doi.org/10.1016/j.jslw.2006.09.006

Leedy, P. D., \& Ormrod, J. E. (2015). Practical research: Planning and design (11 ${ }^{\text {th }}$ ed.). 
Prentice Hall.

Lin, O. P., \& Maarof, N. (2013). Collaborative writing in summary writing: Student perceptions. Procedia - Social and Behavioral Sciences, 90, 599-606. https://doi.org/10.1016/j.sbspro.2013.07.131

Lung, R. I., Moraru, C., Balazsi, R., Both, I., \& Aluaș, M. (2014). Needs analysis as an instrument to design and adapt specific academic writing interventions. Cognition, Brain, Behavior, 18(4), 261-281.

Mackey, A., \& Gass, S. M. (2005). Second language research: Methodology and design. Lawrence Erlbaum

Murphy, A. (2010). Academic writing and publishing matters for the scholar-researcher. Dublin Institute of technology.

Nambiar, R. M. K. (2007). Enhancing academic literacy among tertiary learners: A Malaysian experience. $\quad 3 L$ : Language, Linguistics, Literature ${ }^{\circledR}, \quad 13, \quad 1-21$. http://ejournal.ukm.my/31/article/view/1030

Park, C. (2003). In other (people's) words: Plagiarism by university students-literature and lessons. Assessment \& Evaluation in Higher Education, 28(5), 471-488. https://doi.org/10.1080/0260293032000120352

Qayoom, N., \& Saleem, M. (2020). A study of Saudi advanced academic writing students' perceptions of research essays, and gaps in their knowledge. International Journal of Learning, Teaching and Educational Research, 19(6), 223-237. https://doi.org/10.26803/ijlter.19.6.13

Ratnawati, R., Faridah, D., Anam, S., \& Retnaningdyah, P. (2018). Exploring academic writing needs of Indonesian EFL undergraduate students. Arab World English Journal, 9(4), 420-432. https://doi.org/10.24093/awej/vol9no4.31

Shannon, S. L. (2011). A guide to academic and scholarly writing. Baldwin Book Publishing.

Soehadi, G. (2008). In becoming EFL writing teacher: A diary study. $k @ t a:$ A Biannual Publication on the Study of Language and Literature, 9(2), 141-157. https://doi.org/10.9744/kata.9.2.141-157

Stander, M. (2020). Strategies to help university students avoid plagiarism: a focus on translation as an intervention strategy. Journal of Further \& Higher Education, 44(2), 156-169. https://doi.org/10.1080/0309877x.2018.1526260

White, E. M. (1993, February 24). Too many campuses want to sweep student plagiarism under the rug. The Chronicle of Higher Education. https://www.chronicle.com/article/too-many-campuses-ignore-student-plagiarism/ 


\section{Macrothink}

\section{Appendix}

\section{Interview Question Form}

The interviews were guided by the following basic questions:

1- How do you perceive summarizing and paraphrasing English texts in academic writing?

2- Are there any salient difficulties that you encounter while summarizing and paraphrasing?

3- Among these difficulties, what are the most recurrent, daunting and time consuming ones?

4- To what causes do you attribute these difficulties?

5- How do you deal with such difficulties?

6- Do you suggest certain actions to be taken by the university in order to improve your academic writing skills in general and your summarizing and paraphrasing skills in particular?

\section{Copyright Disclaimer}

Copyright for this article is retained by the author(s), with first publication rights granted to the journal.

This is an open-access article distributed under the terms and conditions of the Creative Commons Attribution license (http://creativecommons.org/licenses/by/3.0/). 